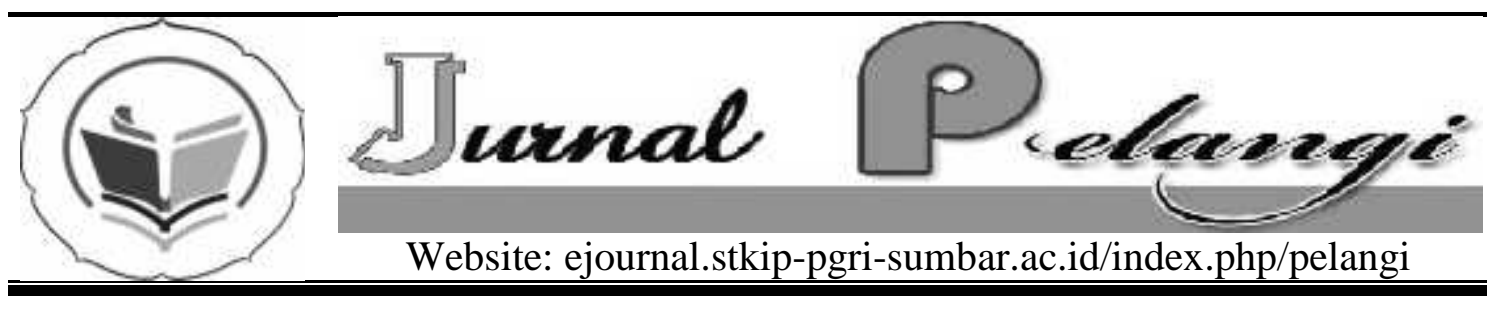

\title{
KEHIDUPAN CORP TJADANGAN NASIONAL (CTN) DI BUKIT NILAM PASAMAN PADA MASA PRRI (1956-1958)
}

\author{
Meldawati \\ STKIP PGRI Sumatera Barat \\ Meldawati_2013@yahoo.co.id
}

\section{INFO ARTIKEL}

\section{Diterima :}

Disetujui :

Kata Kunci:

\section{Kehidupan CTN, PRRI}

\begin{abstract}
Abstrak
Penelitian ini membahas masa depan CTN di Pasaman PRRI. CTN, secara khusus, dipengaruhi oleh rasionalisasi pemberontak terakhir pada cabinet Hatta. CTN adalah orang Jawa yang baik dan berasal dari Yogyakarta, orang-orang Jawa yang telah tinggal di Kalimantan. CTN masuk Pasaman, khususnya pada daerah Bukit Nilam. Hal ini karena desa Bukit Nilam adalah bekas perkebunan Belanda pada munculnya PRRI yaitu peristiwa sentimen terhadap orang Minang Jawa, khususnya di Bukit Nilam. Akibatnya kehidupan CTN menderita. Tujuan dari penelitian ini adalah untuk menggambarkan kedatangan awal CTN di Bukit Nilam Pasaman, dan menggambarkan kehidupan CTN di Bukit Nilam Pasaman pada masa PRRI (1958-1961).

Metode penelitian ini metode sejarah. Awal pengumpulan data (heuristik) adalah mencari dokumen, surat kabar dan buku yang berkaitan dengan kehidupan masa depan CTN PRRI. Wawancara lebih lanjut dilakukan dengan anggota CTN dan orang-orang yang menyaksikan peristiwa PRRI di Pasaman. Setelah data terkumpul, dilakukan kritik sumber, memilahmilah berdasarkan kategori atau fokus penelitian, kemudian, menjelaskannya secara tertulis (historiografi)

Hasil penelitian dapat disimpulkan bahwa CTN di Pasaman adalah mantan jenderal angkatan darat berdarah Jawa yang berasal dari Kalimantan. Alasan CTN untuk datang ke Pasaman karena sulitnya mendapatkan kehidupan yang lebih baik di Kalimantan. CTN Pasaman ditempatkan di daerahdaerah terutama di Bukit Nilam, karena Bukit Nilam adalah mantan perkebunan jaman penjajahan Belanda. Setelah kemerdekaan Indonesia, Bukit Nilam diserahkan kepada pemerintah Indonesia Belanda kerajaan, khususnya Menteri Pertahanan dan Keamanan (Menteri Pertahanan). CTN bertempatlah di Bukit Nilam. Selanjutnya, di awal 1956 kehidupan CTN tidak memiliki masalah, mereka hidup damai dengan orang-orang di sekitar Bukit Nilam. Namun pada
\end{abstract}


tahun 1958 terjadi peristiwa PRRI yang membawa dampak buruk pada kehidupan CTN di Bukit Nilam Pasaman. Ketenangan dan kedamaian yang dinikmati selama dua tahun berakhir dengan pepecahan yang menyebabkan pengusiran, bahkan pembunuhan anggota CTN. CTN dari orang Jawa asli dan pemerintah pusat mendukung sehingga mereka mengalami masalah kehidupan.

Keywords:

Life in of CTN, PRRI

\section{PENDAHULUAN}

CTN merupakan organisasi gerilyawan yang berasal dari reorganisasi dan rasionalisasi ketentaraan yang

\begin{abstract}
This study discusses the future life of CTN in Pasaman PRRI. CTN is specifically affected by the rationalization of past insurgent Hatta cabinet. CTN is a good Javanese who came from Yogyakarta, Java or people who have lived in Borneo. CTN to Pasaman particular arrival to Bukit Nilam, because villages Bukit Nilam is a former Dutch plantation on the emergence PRRI events sentiment against the Minang people of Java, especially in Bukit Nilam. Consequently CTN life suffered. The purpose of this study is: 1) to describe the early arrival of CTN in Bukit Nilam Pasaman?,2) describing life in Bukit Nilam CTN Pasaman PRRI period (1958-1961).

This research method historical method. At the start of data collection (heuristics), which is looking for documents, newspapers and books relating to the future life of CTN PRRI. Further interviews were conducted with members of CTN and people who witnessed the events in Pasaman PRRI. Once the data is collected is done critique sources, sifting through by category or research focus, then describe in writing (historiography)

Results of the study can be concluded: 1) CTN in Pasaman a Javanese former army general who came from Borneo. CTN reason to Pasaman arrival because in Borneo is not possible to live a better life. CTN Pasaman placed in areas especially in Bukit Nilam, because Bukit Nilam is a former Dutch colonial era plantation. After the independence of Indonesia Nilam Bukit submitted by the Dutch royal Indonesian government, particularly the Minister of Defense and Security (Minister of Defense). CTN in Bukit Nilam is placed. 2) in the early 1956 arrival CTN life does not have problems, they live in peace with the people around Bukit Nilam. But in 1958 occurred PRRI events bring bad impact on the lives of CTN in Bukit Nilam Pasaman, tranquility and peace that we have enjoyed for two years now pepecahan that led to the expulsion, even the killing of members of CTN. CTN real Javanese and central government support so that they are experiencing life problems.
\end{abstract}

dilaksanakan oleh kabinet Hatta. Bagi terkena rasionalisasi akan disalurkan ke bidang-bidang produktif yang berguna bagi pembangunan negara. Atas balas jasa maka gerilyawan ini ditampung dalam CTN. 
Pembentukan CTN ini dilatarbelakangi oleh keinginan Hatta melakukan penghematan dalam angkatan perang, karena keadaan ekonomi Indonesia lemah akibat dari blokade ekonomi yang dilakukan oleh Belanda. Secara khusus para gerilyawan yang terkena rasionalisasi ini bukan saja berasal dari orang Jawa Yogyakarta, tetapi juga orang Jawa yang ditugaskan ke Kalimantan pada tahun 1954.

Kedatangan CTN ke Pasaman pada tanggal 22 Februari 1956 ke Bukit Nilam, karena nagari Bukit Nilam merupakan bekas perkebunan Belanda pada masa penjajahan, sesudah Indonesia merdeka Bukit Nilam diserahkan oleh kerajaan Belanda kepada pemerintahan Indonesia, khususnya pada TNI atau Menteri Pertahanan dan Keamanan (Menhankam). Di perkebunan inilah CTN itu ditempatkan.

Pada tahun 1956 rombongan CTN datang ke Bukit Nilam (Kenagarian Aua Kuniang Pasaman). Pemerintah menyediakan tanah dan bedeng sebagai tempat pemukim bagi CTN, akan tetapi bedeng yang dijadikan sebagai tempat tinggal CTN dan keluarganya tidak layak untuk ditempati, rumah yang dijadikan bedeng berukuran $3 \times 6$ dengan satu kamar, tanpa ada dapur.

Saat PRRI meletus anggota CTN menjadi salah satu sasaran dan amukan kemarahan PRRI. Hal ini disebabkan karena CTN orang Jawa dan nyata memihak pada pemerintahan pusat waktu, sehingga membawa akibat buruk bagi mereka yang ada di Bukit Nilam, mereka diganyang, diusir serta tempat tinggal mereka dihancurkan oleh penduduk dan PRRI bahkan merekapun dibunuh. Sebaliknya CTN semakin kuat ketika APRI berhasil menguasai Sumatera Barat, sebahagian anggota CTN ini bergabung dengan tentara APRI dan masuk dalam
Bataliyon 132 yang lebih ganas dari orang PRRI.

\section{METODE PENELITIAN}

Metode penelitian yang dipakai adalah metode sejarah. Metode sejarah menempuh beberapa tahap, yakni heuristik, kritik, interpretasi dan historiografi.

Heuristik : Pada tahap ini melakukan pengumpulan sumber-sumber data yang berhubungan dengan permasalahan yang dibahas. Sumber itu terdiri dari sumber primer dan sekunder. Sumber Primer diperoleh dengan melakukan wawancara dengan pelaku sejarah, seperti dengan anggota Corp Tjadangan Nasional (CTN) yang masih hidup, masyarakat Bukit Nilam yang menjadi saksi dari peristiwa tersebut. Untuk sumber sekunder yaitu berupa buku dan skripsi yang penulis peroleh di Perpustakaan Universitas Negeri Padang, Perpustakaan STKIP PGRI.

Kritik Sumber : Tahap kedua dilakukan kritik sumber, yaitu setelah semua sumber ditemukan, data-data yang telah dikumpulkan dari berbagai jenis sumber tersebut kemudian dianalisis melalui kritik sumber. Kritik sumber yang dimaksud meliputi kritik ekstern dan intern. Kritik intern pada sumber lisan sebenarnya telah dimulai sejak penetapan nama-nama informan yang akan di wawancara. Beberapa kriteria yang digunakan adalah keterkaitan informan dengan peristiwa CTN pada masa PRRI, contohnya anggota CTN itu sendiri yang masih hidup, masyarakat Bukit Nilam yang mengetahui kehidupan CTN pada masa PRRI. Adapun tujuan yang diinginkan adalah untuk menghindari informasi yang palsu atau tidak benar. Sementara kritik ekstern pada sumber tertulis bertujuan untuk mengkaji kebenaran isi data, dengan prosedur pemeriksaan kertas, tinta dan kategori sumber. Penilaian ini akan terlihat dari 
sumber luar, seperti sumber yang pertama atau berbentuk sumber yang telah digandakan (foto copy). Bila telah diyakini keaslian sumber baru dilanjutkan dengan menguji kebenaran isi. Untuk melakukan itu penulis akan menempuh cara perbandingan antar sumber, ejaan dan bahasa yang digunakan, dan juga uraian yang ditulis. Adapun tujuannya adalah agar dapat melihat isi sumber yang digunakan.

Interpretasi : Proses ini adalah suatu proses menginterpretasikan dan menganalisa fakta dengan cara menghubungkan fakta yang satu dengan fakta yang lainnya sesuai dengan konteks peristiwa. Pada tahap ini mulai dikaji sebab peristiwa terjadinya dan mengkaitkan dengan sebab akibat dengan peristiwa tersebut. Hal yang paling penting dalam proses ini adalah membedakan antara akibat dan sebab.

Historiografi :Tahap ini merupakan langkah akhir penelitian dengan menghasilkan suatu karya ilmiah sejarah khususnya tentang kehidupan Corp Tjadangan Nasional (CTN) Di Bukit Nilam Pasaman pada masa PRRI (1956-1958).

\section{HASIL DAN PEMBAHASAN}

\section{Kedatangan CTN di Bukit Nilam Kabupaten Pasaman}

CTN di Pasaman adalah orang Jawa berasal dari Kalimantan, CTN awalnya adalah sebahagian bekas tentara. Hal ini sebagaimana yang dijelaskan oleh tulisan Eni May, bahwa pada tahun 1952-1960 di samping dikirim transmigrasi umum juga ada transmigrasi khusus yang sebahagian adalah bekas tentara yang terindikasi CTN.

Latarbelakang kedatangan CTN ke Kalimantan sebagai mana pernyataan Sangidi adalah, "latarbelakang kedatangan orang Jawa ke daerah Kalimantan pada tahun 1951 adalah untuk latihan dan dimasukkan dalam Corp Tjadangan Nasional, Selanjutnya menurut Narkim
CTN berasal dari Kalimantan tepatnya daerah Puruk Jao. CTN menurut Narkim adalah bekas tentara, walaupun hidupnya sewaktu berada di Kalimantan sebagai petani.

CTN yang berasal dari Kalimantan umumnya mereka adalah orang Jawa Tengah, Jawa Timur dan Yogyakarta. Awalnya CTN adalah gerilyawan yang berasal dari Rera, bekas tentara yang ditugaskan menjaga keamanan dan dipersenjatai sebagai tentara dan menerima gaji setiap bulannya. Alasan kedatangan CTN ke Pasaman karena sewaktu di Kalimantan tidak memungkinkan untuk CTN hidup lebih baik. Hal ini disebabkan keadaan tanah yang tidak subur. Senada dengan pernyataan diatas bahwa CTN memang berasal dari Kalimantan, sebagaimana yang ditulis dalam Surat Kabar Haluan, usaha penampungan CTN di wilayah propinsi Kalimantan yang telah dilakukan oleh kepala staf Angkatan Darat dengan rektorat CTN sebagai organisasi pelaksananya yang dilanjutkan oleh Biro Penampungan Bekas Anggota Tentara. Pada beberapa daerah di Kalimantan tanahnya tidak memungkinkan untuk berhasil karena tidak subur, maka dilakukan pemindahan ke daerah atau objek baru.

Berbeda dengan pernyataan di atas berdasarkan wawancara dengan Sangidi, yang menyatakan bahwa alasan CTN pindah ke Pasaman adalah untuk dilatih dan dipindah tugaskan. Selain itu karena di Pasaman terdapat kapling-kapling tanah milik MENHANKAM tepatnya di Bukit Nilam. Oleh karena itu pada tahun 1956 CTN di pindahkan ke Pasaman tepatnya di daerah Bukit Nilam. Pernyataan tentang kedatangan CTN yang dituturkan oleh Narkim di daerah Pasaman pada tahun 1956 senada dengan yang pernyataan Gusti Asnan. 
Pada tanggal 20 bulan Februari tahun 1956 setengah bataliyon CTN tiba di Pasaman, terdiri dari 500 orang tentara, serta 150 orang wanita dan anak-anak. Anggota CTN berangkat menuju Sumatera Barat dengan menggunakan jalur laut. Mereka diangkut dengan menggunakan kapal milik Tentara Republik Indonesia dengan nama kapalnya KPM Djenderal Michels Menempuh perjalanan lebih kurang tujuh hari atau hampir satu minggu dari Kalimantan, maka pada tanggal 18 tepatnya bulan Februari tahun 1956 rombongan CTN ini tiba di pelabuhan Teluk Bayur, kemudian setelah dua hari berada di Teluk Bayur pada tanggal 20 Februari 1956 mereka langsung diberangkatkan menuju Pasaman. Mereka terdiri dari tentara, bekas tentara beserta istri, dan anak-anaknya. Setelah menempuh perjalanan dua hari, maka pada siang hari sekitar jam 2 tepatnya pada hari Rabu tanggal 22 Februari tahun 1956 rombongan CTN sampai di Pasaman, dan mereka di tempatkan di Bukit Nilam sebanyak 400 orang, karena kondisi bedeng sebagai tempat tinggal sangat terbatas menyebabkan CTN menyebar dan membangun pemukiman sendiri di daerah lainnya seperti, Aia Dingin 100 orang, Sungai Batuang 80 orang, Kampuang Pinang 50 orang dan Jambak 20 orang. Pembangunan bedeng tidaklah mudah karena kondisi daerah yang masih hutan belantara butuh waktu untuk membangunnya. Untuk tempat tinggal bagi para anggota CTN, pemerintah telah menyiapkan bedeng-bedeng di Bukit Nilam untuk masing-masing keluarga disediakan tanah seluas 0,5 ha. Rumah sebagai tempat tinggal CTN adalah rumah bedeng yang berukuran 3x6 dengan satu kamar. Areal pemukiman dan tanah untuk lahan perkebunan yang diberikan kepada CTN merupakan tanah milik MENHANKAM yang dikenal dengan tanah Pancang
Merah. Tanah ini sebelumnya milik pemerintah kolonial Belanda, namun setelah kemerdekaan tanah ini diambilalih oleh Pemerintah yang dikenal dengan tanah MENHANKAM.

Status CTN adalah bekas tentara cadangan, yang masih menerima tanggungan dari pemerintah pusat. santunan yang diterima oleh anggota CTN perbulannya sebesar 150 perak. Hampir kurang dua tahun CTN menggantungkan hidup keluarganya dari bantuan yang diberikan oleh pemerintah. Kemudian mereka beralih untuk bercocok tanam karena tanah yang subur.

Kedatangan CTN ke Pasaman juga menimbulkan kekhawatiran sebab mereka orang Jawa yang berbeda dengan adat dan tradisi masyarakat Pasaman yang umumnya orang Minangkabau, persoalan ini tidak begitu menimbulkan persoalan yang berat selagi orang CTN mau mengikuti adat dan aturan masyarakat Minang khususnya masyarakat di daerah Bukit Nilam.

\section{b. Kehidupan CTN di Bukit Nilam Kabupaten Pasaman masa PRRI (1958-1961).}

Pada awal kedatangan tahun 1956 di Bukit Nilam pada mulanya anggota CTN masih menggantungkan sepenuhnya pada santunan yang diberikan pemerintah pusat. Lebih kurang dua tahun CTN mulai dengan kehidupan membuka perladangan, yaitu menggarap hutan belantara dijadikan sebagai ladang yang masih menggantungkan kesuburan tanah dari turunnya hujan.

Pada mulanya bertani dijadikan sebagai pekerjaan sampingan, karena luasnya tanah di Pasaman khususnya daerah Bukit Nilam masih terdapatnya banyak tanah yang belum diolah sebagaimana penuturan pak Sangidi: "Dulu ketika awal datang kira-kira bulan Februari tahun 1956 daerah ini masih hutan belantara, jalannya masih jalan setapak. 
Dengan terbukanya daerah hutan belantara menjadi daerah perladangan, maka orang CTN tertarik untuk bertani dan berladang. Hasil yang didapat dari bertani cukup untuk memenuhi kebutuhan hidup CTN, maka mereka mulai beralih pandangan dengan menjadikan pertanian sebagai mata pencaharian pokok. Orang CTN menanam tanaman seperti ubi, kacang dan jenis tanaman lainnya, kemudian CTN juga membuat ladang padi untuk memenuhi kebutuhan pangan mereka. Hasil ladang digunakan untuk memenuhi kebutuhan hidup keluarganya.

Dari segi kepercayaan umumnya anggota CTN yang datang ke Bukit Nilam adalah beragama Islam, tetapi mereka belum sempat membangun sarana tempat peribadatan. Untuk beribadah mereka melaksanakan di tempat tinggalnya saja, kecuali pada hari-hari besar Islam, seperti sholat Idul Fitri, mereka pergi ke Simpang Empat, atau ke Simpang Tiga, yang jaraknya sekitar $12 \mathrm{~km}$ dari tempat mereka tinggal. Untuk kebutuhan pendidikan anakanak CTN, mereka menyekolahkannya ke Simpang Empat, karena pada waktu itu di Bukit belum dibangun sekolah sebagai sarana pendidikan. Untuk pergi ke sekolah anak-anak mereka harus menempuh perjalanan yang cukup jauh. Namun karena sebagian dari anggota CTN memiliki semangat belajar yang cukup tinggi membuat mereka tetap menyekolahkan anaknya ke Simpang Empat, sebagai transportasi untuk berangkat ke sekolah adalah sepeda.

Dari segi sosial budaya, umumnya CTN ini menganut kebudayaan Jawa, walaupun sebahagian dari mereka pernah tinggal di Kalimantan. Mereka masih memegang teguh adat istiadat asli. Bahasa yang mereka pakai sehari-hari adalah bahasa Jawa, awalnya ini menjadi kendala dalam berinteraksi dengan masyarakat sekitar Bukit Nilam. Penggunaan adat Jawa tampak pada acara-acara kesenian yang mereka lakukan, seperti kesenian wayang kulit. Perbedaan sosial budaya antara CTN dengan penduduk di sekitar Bukit Nilam tidak menjadi penghambat untuk saling berinteraksi. Walaupun terkendala dengan bahasa pada awalnya, kerukunan selalu diusahakan dengan masyarakat disekitar mereka tinggal. Setelah hampir dua tahun berbaur dengan masyarakat sekitar Bukit Nilam khususnya sebelum terjadi peristiwa PRRI malahan adanya istilah pertandangan (berkunjungnya seseorang kerumah tetangganya yang masih dalam lingkungan yang sama) yang merupakan wadah untuk saling mempererat tali silaturrahmi antara CTN dengan penduduk di sekitar Bukit Nilam. Orang CTN juga sangat memegang teguh ajaran agama dan adat istiadatnya dalam melaksanakan kehidupannya.

Adanya budaya gotong royong di antara anggota CTN, maupun penduduk asli, juga merupakan sarana untuk terjalinnya hubungan baik antara masyarakat setempat dengan CTN yang berlangsung sebelum terjadinya peristiwa PRRI. Dalam kehidupan sehari-hari mereka saling menjaga ketenangan dan keamanan lingkungan. CTN menyadari bahwa sebagai pendatang di daerah baru, dan merasa senasib sepenanggungan, maka mereka tidak saling menyakiti atau mencari masalah sehingga nantinya akan dapat memicu terjadinya perpecahan diantara mereka.

Secara nyata sejak kedatangan mereka tahun 1956, sampai terjadinya peristiwa PRRI, kehidupan bekas para tentara ini tidak begitu mengalami permasalahan, namun saat pecahnya peristiwa PRRI pada awal tahun 1958, yang dipandang oleh pemerintah sebagai pemberontakkan daerah terhadap negara kesatuan Republik Indonesia. Maka sejak itulah CTN ini mengalami masalah, dikarenakan mereka menyatakan mendukung pemerintah 
dengan menerima bantuan senjata dari daerah pusat melalui Pelabuhan Sasak.

PRRI yang identik dengan Sumatera Tengah atau luar Jawa, sementara CTN adalah dari Jawa dan cenderung memihak pemerintah pusat. Inilah yang pada akhirnya membawa masalah besar dan mala petaka bagi kehidupan anggota CTN . Dengan terjadinya peristiwa PRRI ketenangan dan kedamaian yang telah dinikmati selama dua tahun kini menjadi

\section{KESIMPULAN DAN SARAN}

CTN di Pasaman adalah orang Jawa berasal dari Kalimantan, CTN awalnya adalah sebahagian bekas tentara. CTN yang berasal dari Kalimantan di pindahkan ke Pasaman dengan alasan dilatih dan dipindah tugaskan. Selain itu karena di Pasaman terdapat kapling-kapling tanah milik MENHANKAM tepatnya di Bukit Nilam. Oleh karena itu pada tahun 1956 CTN di pindahkan ke Pasaman tepatnya di daerah Bukit Nilam.

Pada tanggal 20 bulan Februari tahun 1956 setengah bataliyon CTN tiba di Pasaman, terdiri dari 500 orang tentara, serta 150 orang wanita dan anak-anak. Anggota CTN berangkat menuju Sumatera Barat dengan menggunakan jalur laut. Mereka diangkut dengan menggunakan kapal milik Tentara Republik Indonesia dengan nama kapalnya KPM Djenderal Michels. Untuk tempat tinggal bagi para anggota CTN, pemerintah telah menyiapkan bedeng-bedeng di Bukit Nilam, rumah untuk tempat tinggal adalah rumah bedeng yang berukuran $3 \times 6$. Tanah yang diberikan untuk CTN merupakan tanah milik MENHANKAM yang dikenal dengan tanah Pancang Merah.Pada awal kedatangan tahun 1956 di Bukit Nilam pada mulanya anggota CTN masih menggantungkan sepenuhnya pada santunan yang diberikan pemerintah pusat. perpecahan yang berujung dengan pengusiran, bahkan pembunuhan terhadap para anggota CTN. CTN yang pro pusat sehingga menimbulkan konflik dengan PRRI, Apalagi CTN nyata menerima senjata dari pemerintah pusat inilah penyebab munculnya konflik yang berujung dengan kekerasan dilakukan oleh masyarakat dan simpatisan PRRI di Bukit Nilam.

Dalam hal kepercayaan umumnya anggota CTN yang datang ke Bukit Nilam adalah beragama Islam, untuk beribadah mereka melaksanakan di tempat tinggalnya saja, kecuali pada hari-hari besar Islam, seperti sholat Idul Fitri, mereka pergi ke Simpang Empat, atau ke Simpang Tiga. Untuk kebutuhan pendidikan anak-anak CTN, mereka menyekolahkannya ke Simpang Empat, karena pada waktu itu di Bukit Nilam belum tersedianya sekolah. Dari segi sosial budaya, umumnya CTN ini menganut kebudayaan Jawa, mereka masih memegang teguh adat istiadat asli.

Secara nyata sejak kedatangan anggota CTN tahun 1956, sampai terjadinya peristiwa PRRI, kehidupan bekas para tentara ini tidak begitu mengalami permasalahan, namun saat pecahnya peristiwa PRRI pada awal tahun 1958, yang dipandang oleh pemerintah sebagai pemberontakkan daerah terhadap negara kesatuan Republik Indonesia. Maka sejak itulah CTN ini mengalami masalah, dikarenakan mereka menyatakan mendukung pemerintah dengan menerima bantuan senjata dari daerah pusat melalui Pelabuhan Sasak.

Dengan terjadinya peristiwa PRRI ketenangan dan kedamaian yang telah dinikmati selama dua tahun kini menjadi perpecahan yang memicu munculnya konflik yang berujung dengan kekerasan 
dilakukan oleh masyarakat dan simpatisan PRRI di Bukit Nilam.

Berdasarkan permasalahan yang penulis temukan melalui penelitian, maka disaran, hendaknya Pemerintah Pusat belajar dari masa lalu bagaimana seharusnya menghadapi permasalahan, konflik dan kekerasan jangan terulang lagi, karena kekerasan dan konflik akan merusak keutuhan bangsa dan Negara. Oleh karena itu walaupun kita berbeda suku, agama dan bahasa kita tetap bersaudara dan hidup rukun.

\section{UCAPAN TERIMAKASIH}

Penelitian ini terselenggara atas bantuan yayasan PGRI Padang dan Kepala Perpustakaaan Universitas Negeri Padang yang telah menyediakan fasilitas ruang baca dan referensi.

\section{DAFTAR PUSTAKA}

Aderito de Jesus Soares.dkk. (1997) Tahun Kekerasan Potret Pelanggaran HAM di Indonesia Jakarta: Yayasan Lembaga Bantuan Hukum Indonesia.

Amrin Imran. (1988) Ikhtisar Sejarah Perang Kemerdekaan di Sumatera (1945-1949), (Markas Besar Angkatan Bersenjata Republik Indonesia, Pusat Sejarah dan Tradisi ABRI

Basri.Ms. (2006) Metodologi Penelitian Sejarah (Pendekatan, Teori dan Praktik), Jakarta: Restu Agung.

Bismo. Hardjo.2000. Sejenak Sejarah Keberadaan Orang-orang Indonesia Di Suriname Sampai proses Kepulangannya ke Indonesia ( belum di terbitkan )

Cribb, Robert. 2003, Pembantaian PKI Di Jawa Dan Bali 1965-1966, Yogjakarta: Mata Bangsa
Dudung Abdurrahman. (2007) Metodologi Penelitian Sejarah, Jogjakarta: Ar-ruzz Media
Gusti Asnan. (2007) "PRRI Penulisan Sejarah Dan Kekerasan", Jurnal Sejarah Pemikiran Rekontruksi persepsi, 13(13), YMSI dan Yayasan Obor Indonesia.

